Table 1

\begin{tabular}{|c|c|c|c|c|c|}
\hline \multirow[b]{2}{*}{ Number } & \multicolumn{2}{|c|}{ Baseline } & \multicolumn{2}{|c|}{3 months } & \multirow{2}{*}{$\begin{array}{l}\text { Adjusted } \beta \text { for } \\
\text { comparison at } \\
\text { 3- months } \\
(95 \% \mathrm{Cl})\end{array}$} \\
\hline & $\begin{array}{c}\text { TNFi } \\
\text { Mean(SE) }\end{array}$ & $\begin{array}{c}\text { Exercise } \\
\text { Mean(SE) }\end{array}$ & $\begin{array}{c}\text { TNFi } \\
\text { EMM (SE) }\end{array}$ & $\begin{array}{l}\text { Exercise } \\
\text { EMM(SE) }\end{array}$ & \\
\hline
\end{tabular}

Primary outcomes

$\begin{array}{lllllll}\text { ASDAS } & 3.16(0.05) & 2.45(0.12) & 2.13(0.06) & 1.88(0.15) & -0.25(0.56,0.05) & 0.11\end{array}$ BASDAl total $\quad 5.92(0.08) 4.94(0.22) 3.89(0.12) 3.72(0.32)-0.18(-0.85,0.50) 0.61$ BASDAI subscores

$\begin{array}{llllllll}\text { Fatigue } & 6.60(0.11) & 5.8(0.25) & 4.63(0.14) & 4.06(0.39) & -0.57(-1.39,0.25) & 0.17\end{array}$ $\begin{array}{llllllll}\text { Pain } & 6.48(0.11) & 5.8(0.27) & 4.29(0.15) & 3.89(0.39) & -0.39 & (-1.21,0.42) & 0.35\end{array}$ $\begin{array}{llllllll}\text { Peripheral arthritis } 4.41(0.15) & 3.76(0.31) & 3.10(0.13) & 2.64(0.35) & -0.45 & (-1.18,0.29) & 0.23\end{array}$ $\begin{array}{lllllllll}\text { Enthesitis } & 5.41(0.13) & 4.46(0.33) & 3.54(0.14) & 3.30(0.39) & -0.24(-1.06,0.58) & 0.57\end{array}$ Stiffness intensity $6.75(0.11) \quad 5.42(0.30) \quad 4.01(0.14) \quad 3.86(0.37) \quad-0.16(-0.95,0.63) \quad 0.70$ Stiffness duration $6.66(0.15) \quad 4.32(0.35) \quad 4.17(0.15) \quad 3.93(0.41) \quad-0.24(-1.11,0.63) \quad 0.59$ Soluble biomarker

CRP

$7.94(0.72) \quad 4.12(0.71) \quad 3.81(0.38) \quad 3.95(0.95) \quad 0.13(-1.88,2.15) \quad 0.90$

Adjusted $\beta$ derived from ANCOVA models adjusted for age, gender and baseline values Disease activity at 3 months was the dependent variable in the models. EMM: Estimated marginal means.

Figure 1 Standard mean difference in change in disease outcomes at 3 months

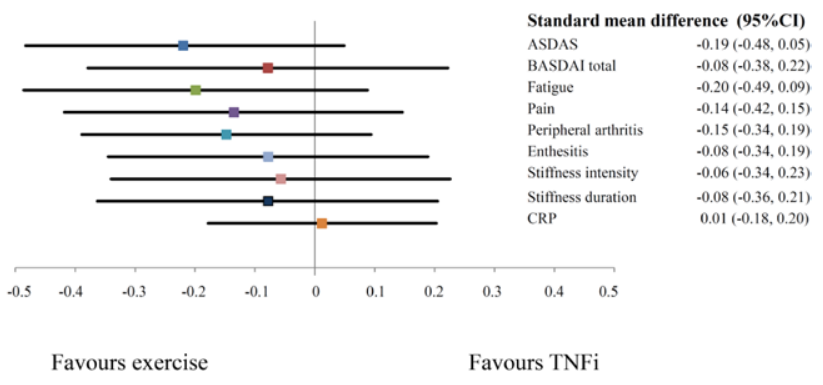

Conclusion: High intensity exercise has comparable 3-month effectiveness to TNF-inhibitors, in patients with axSpA. This confirms the important role of high-intensity exercise in the treatment of axSpA.

References:

[1] Sveaas $\mathrm{SH}$ et al. High intensity exercise for 3 months reduces disease activity in axial spondyloarthritis (axSpA): a multicentre randomised trial of 100 patients. Br J Sports Med. 2019.

[2] Kvien TK et al. A Norwegian DMARD register: prescriptions of DMARDs and biological agents to patients with inflammatory rheumatic diseases. ClinExpRheumatol. 2005;23(5 Suppl 39):S188-S94.

Disclosure of Interests: Sella Aarrestad Provan Consultant of: Novartis, Eirik kristianslund: None declared, Inger Jorid Berg: None declared, Hanne Solveig Dagfinrud: None declared, Silje Halvorsen Sveaas: None declared DOI: 10.1136/annrheumdis-2020-eular.5821

\section{THU0372 EFFECTIVENESS OF STEROID INJECTION FOR HAND PSORIATIC DACTYLITIS: RESULTS FROM A MULTICENTRE PROSPECTIVE OBSERVATIONAL STUDY.}

N. Girolimetto ${ }^{1}$, G. Citriniti', I. Tinazzi ${ }^{2}$, P. Macchioni' ${ }^{1}{ }^{1}$ Unit of Rheumatology, Department of Rheumatology, Reggio Emilia, Italy; ${ }^{2}$ Unit of Rheumatology, Sacro Cuore Don Calabria Hospital, Negrar, Italy

Background: Dactylitis is a common feature of PsA, occurring in 16 to $49 \%$ of PsA patients, mostly in early disease.
Objectives: To assess the effectiveness of steroid injection (local treatment, LT) into the digital flexor tendon sheath for the treatment of active dactylitis in PsA patients as compared to systemic treatment (ST) alone.

Methods: 73 hand dactylitis were assessed in a prospective observational study by the Leeds Dactylitis Index basic (LDI-b) score and evaluated for pain (VAS pain), functional impairment (VAS-FI). In accordance with EULAR and GRAPPA recommendations, steroid injection was proposed to all patients. Patients who refused LT were treated with oral NSAIDs. The patients of the two groups continued baseline therapy with csDMARDs or corticosteroids. The clinical outcomes were measured at baseline, 1 month (T1) and 3 months (T3) by assessors blinded to this study.

Results: The reduction of VAS-pain, VAS-FI and LDI-b values was statistically significant higher in the LT group as compared to the ST group, both at T1 ( $p<0.001, p<0.001$ and $p=0.008$, respectively) and at $T 3(p<0.001, p<0.001$ and $p<0.001$, respectively) (see Table 1). A clinically meaningful treatmen response was observed at T1 in $33(87 \%)$ digits in LT group and in $6(17 \%)$ digits in ST group $(p<0.001)$. At T3, clinical response improved significantly in both the groups, with significant difference (see Table 2). In both the groups, no local and systemic adverse events were observed during the follow up period.

Table 2. Percentage of Significant response and Remission of dactylitis.

\begin{tabular}{llll}
\hline & & T1 1 month & T3 3 months \\
\hline Significant response, $\mathrm{n}(\%)$ & LT & $33(86.8 \%)$ & $36(94.7 \%)$ \\
& ST & $6(17.1 \%)$ & $11(31.4 \%)$ \\
Remission & p value & $<0.001$ & $<0.001$ \\
$\mathrm{n}(\%)$ & LT & $1(2.8 \%)$ & $7(18.4 \%)$ \\
& ST & $0(0 \%)$ & $0(0 \%)$ \\
& p value & ns & $\mathbf{0 . 0 1 2}$ \\
\hline
\end{tabular}

Values are presented as number of dactylitic fingers achieving response/remission. $p$ values 0.05 were considered statistically significant.

Conclusion: For the first time, we show the effectiveness of steroid injection into the digital flexor tendon sheath in improving clinical aspects and symptoms of hand psoriatic dactylitis.

References:

[1] Gladman DD, Ziouzina O, Thavaneswaran A, Chandran V. Dactylitis in psoriatic arthritis: prevalence and response to therapy in the biologic era. J Rheumatol. 2013;40:1357-9.

Disclosure of Interests: None declared

DOI: 10.1136/annrheumdis-2020-eular.6036

\section{\begin{tabular}{|l|l}
\hline THU0373 SECUKINUMAB DOSE ESCALATION ON ACR \\
\hline
\end{tabular} RESPONSES IN ANTI-TUMOUR NECROSIS FACTOR NAÏVE PATIENTS WITH PSORIATIC ARTHRITIS: 2-YEAR DATA FROM THE PHASE 3 FUTURE 4 AND FUTURE 5 STUDIES}

P. Emery ${ }^{1}$, M. Ǿstergaard ${ }^{2}$, L. C. Coates ${ }^{3}$, A. Deodhar ${ }^{4}$, E. Quebe-Fehling ${ }^{5}$, P. Pellet ${ }^{5}$, L. Pricop ${ }^{6}$, C. Gaillez ${ }^{5}$, F. Van den Bosch ${ }^{7,8}$. ${ }^{1}$ University of Leeds, Leeds, United Kingdom; ${ }^{2}$ Copenhagen University, København, Denmark; ${ }^{3}$ University of Oxford, Oxford, United Kingdom; ${ }^{4}$ Oregon Health \& Science University, Portland, United States of America; ${ }^{5}$ Novartis Pharma AG, Basel, Switzerland; ${ }^{6}$ Novartis Pharmaceuticals Corp., East Hanover, United States of America; ${ }^{7}$ Ghent University Hospital, Ghent, Belgium; ${ }^{8}$ VIB Inflammation Research Centre, Ghent University, Ghent, Belgium

Background: Secukinumab (SEC) 150 and $300 \mathrm{mg}$ doses are approved for the treatment of psoriatic arthritis (PSA). SEC $300 \mathrm{mg}$ is the recommended dose for patients (pts) with concomitant moderate-to-severe plaque psoriasis or who are anti-tumour necrosis factor (TNF) inadequate responders. An increase from

Table 1. Variation of clinical parameters during follow up.

\begin{tabular}{|c|c|c|c|c|c|c|}
\hline & & T0 baseline & T1 1 month & T3 3 months & T0 vs T1 $95 \% \mathrm{Cl}$ & T0 vs T3 $95 \% \mathrm{Cl}$ \\
\hline \multirow[t]{3}{*}{ VAS - PAIN } & LT & $6.89 \pm 1.93$ & $1.97 \pm 1.62$ & $1.34 \pm 1.48$ & $4.92(4.17 ; 5.67)$ & $5.55(4.76 ; 6.32)$ \\
\hline & ST & $6.03 \pm 2.43$ & $5.49 \pm 2.53$ & $5.0 \pm 2.65$ & $0.54(-0.23 ; 1.32)$ & $1.03(-0.02 ; 2.07)$ \\
\hline & Mean differences $(95 \% \mathrm{Cl})$ & $0.87(-1.89 ; 0.16)$ & $3.51(2.53 ; 4.49)$ & $3.66(2.67 ; 4.65)$ & & \\
\hline \multirow[t]{3}{*}{ VAS - FI } & LT & $7.87 \pm 1.53$ & $2.76 \pm 1.87$ & $1.68 \pm 1.54$ & $5.11(4.49 ; 5.72)$ & $6.18(5.52 ; 6.84)$ \\
\hline & ST & $6.89 \pm 1.92$ & $6.14 \pm 2.25$ & $5.74 \pm 2.63$ & $0.74(0.23 ; 1.26)$ & $1.14(0.32 ; 1.97)$ \\
\hline & Mean differences $(95 \% \mathrm{Cl})$ & $0.98(-1,79 ; 0,17)$ & $3.38(2.42 ; 4.34)$ & $4.05(3.06 ; 5.05)$ & & \\
\hline \multirow[t]{3}{*}{ Finger circumference $(\mathrm{cm})$} & LT & $7.17 \pm 0.57$ & $6.61 \pm 0.59$ & $6.55 \pm 0.54$ & $0.56(0.46 ; 0.65)$ & $0.62(0.52 ; 0.73)$ \\
\hline & ST & $7.05 \pm 0.80$ & $6.90 \pm 0.89$ & $6.88 \pm 0.91$ & $0.15(0.06 ; 0.25)$ & $0.17(0.07 ; 0.27)$ \\
\hline & Mean differences $(95 \% \mathrm{Cl})$ & $0.12(-0.44 ; 0.21)$ & $0.29(-0.07-0.69)$ & $0.33(-0.02-0.68)$ & & \\
\hline \multirow[t]{3}{*}{ LDI-b } & LT & $12.31 \pm 0.03$ & $9.91 \pm 7.15$ & $1.25 \pm 4.35$ & $8.40(5.73 ; 11.06)$ & 11.05 (8.22; 13.89) \\
\hline & ST & $14.97 \pm 11.07$ & $9.88 \pm 10.98$ & $10.04 \pm 11.09$ & $5.10(1.63 ; 8.55)$ & $4.93(1.54 ; 8.32)$ \\
\hline & Mean differences $(95 \% \mathrm{Cl})$ & $2.67(-1.82 ; 7.16)$ & $5.97(1.58 ; 10.35)$ & $8.79(4.74 ; 12.83)$ & & \\
\hline
\end{tabular}

